\title{
Experimental Study of On-Body Radio Channel Performance of a Compact Ultra Wideband Antenna
}

\author{
Mohammad Monirujjaman Khan 1,2, Qammer H. Abbasi2,3, Mirazur Rahman", \\ Ratil Hasnat Ashique ${ }^{4}$ \\ ${ }^{1}$ Electronics and Telecommunication Engineering, University of Liberal Arts Bangladesh, Dhaka, Bangladesh \\ ${ }^{2}$ School of Electronic Engineering and Computer Science, Queen Mary University of London, London, UK \\ ${ }^{3}$ Texas A\&M University at Qatar, Al Rayyan, Qatar \\ ${ }^{4}$ Electrical and Electronic Engineering, Primeasia University, Dhaka, Bangladesh \\ Email: monirkhan.qmul@gmail.com
}

Received 12 December 2014; accepted 25 December 2014; published 15 January 2015

Copyright $(2015$ by authors and Scientific Research Publishing Inc.

This work is licensed under the Creative Commons Attribution International License (CC BY).

http://creativecommons.org/licenses/by/4.0/

(c) (i) Open Access

\begin{abstract}
In this paper, on-body radio channel performance of a compact ultra wideband (UWB) antenna is investigated for body-centric wireless communications. Measurement campaigns were first done in the chamber and then repeated in an indoor environment for comparison. The path loss parameter for eight different on-body radio channels has been characterized and analyzed. In addition, the path loss was modeled as a function of distance for 34 different receiver locations for propagation along the front part of the body. Results and analysis show that, compared with anechoic chamber, a reduction of $16.34 \%$ path loss exponent is noticed in indoor environment. The antenna shows very good on-body radio channel performance and will be a suitable candidate for future efficient and reliable body-centric wireless communications.
\end{abstract}

\section{Keywords}

On-Body Radio Channel, Path Loss, Ultra Wideband (UWB) Antenna, Body-Centric Wireless Communications

\section{Introduction}

Ultra wideband communication is an exciting and innovative technology which has become a very promising candidate for future short-range indoor high-speed data communication [1]. The UWB technology offers high 
data rate communication links and low power emission level, in addition to less complex system designs which make it a promising technology for wireless body area networks (WBANs). Its low power requirement due to control over duty cycle allows longer battery life and also introduces green radio system. In body-centric wireless networks, various units/sensors are scattered on/around the human body to measure specified physiological data, as in patient monitoring for healthcare applications [1]-[3]. A body-worn base station will receive the medical data measured by the sensors located on/around the human body. Antenna plays a vital role in bodycentric wireless communications. Body-centric wireless networks have a range of applications, from monitoring of patients with chronic diseases and care for the elderly, to general well-being monitoring and performance evaluation in sports [1]-[7].

The human body is a hostile environment from a radio propagation perspective and it is therefore important to understand and characterize the effects of the human body on the radio channel parameters. The human body tissue is a lossy medium; hence, the wave propagating within the WBAN faces large attenuation before reaching the specified receiver. The design of a power-efficient and reliable on-body communication system requires suitable antennas which therefore require accurate understanding of the human body effects on the antenna performance parameters and radio propagation channels [8]. Researchers have been comprehensively investigating narrow band and ultra wideband on-body radio channels in the past few years. In [9]-[16], on-body radio channel characterization was presented at the unlicensed frequency band of $2.45 \mathrm{GHz}$. In [3] [17]-[22], ultra wideband (UWB) on-body propagation channels have been characterized and their behavior has been investigated in indoor and chamber for stand-still, various postures and dynamic human body. In previous studies, it is shown that different antennas have different on-body radio channel performances. However, the antennas presented and used in previous studies were large in physical size. In this paper measurement campaigns were performed in the chamber and indoor environment using a compact printed quasi-self-complementary ultra wideband (UWB) antenna. The major plan of this study is to investigate and analyze the on-body radio channels performance of the abovementioned compact UWB antenna. The path loss parameter has been characterized and analyzed for eight different on-body radio channels. In addition, the path loss exponent has been extracted for thirty-four different receiver locations on the front part of the human body using least square fit method.

The rest of the paper is organized as follows: Section 2 illustrates the measurement setup and the antenna used for this study; Section 3 presents measurement results, radio channel parameters and modelling aspects; and finally Section 4 draws the main conclusion.

\section{Measurement Setup}

In this study, the on-body radio channel performance of the compact quasi-self-complementary UWB antenna has been experimentally investigated. The S21 measurement campaigns of the compact UWB antenna were performed first in an anechoic chamber and then repeated in the indoor environment. In this experiment, an average-sized real male test subject, with a height of $1.74 \mathrm{~m}$ and a weight of $80 \mathrm{~kg}$ was used. A pair of compact quasi-self-complementary UWB antennas was used. A HP8720ES vector network analyzer (VNA) was used to measure the transmission response (S21) in the frequency range of 3 - $10 \mathrm{GHz}$ between two antennas of the same type placed on the body. The frequency range was set to 3 - $10 \mathrm{GHz}$, with 1601 points and with a sweep time of 800 ms. Table 1 shows the network analyzer settings. During the measurement, the transmitter quasi-self-complementary UWB antenna connecting with the cable was placed on the left waist and the receiver quasi-self-complementary UWB antenna was sequentially attached on 8 different locations on the front part of the body as shown in Figure 1. The test subjects were standing still during the measurements and, for each receiver location and measurement scenario, 10 sweeps were considered.

The effects of the cable were calibrated out. The measurement campaigns were performed in the Body-Cen-

Table 1. Network analyzer settings.

Table 1. Network analyzer settings.
\begin{tabular}{cc} 
Frequency Band & 3 to $10 \mathrm{GHz}$ \\
Frequency Points & 1601 \\
Sweep Time & $800 \mathrm{~ms}$ \\
Number of Sweep & 10 \\
VNA Transmit Power & $0 \mathrm{dBm}$ \\
\hline
\end{tabular}




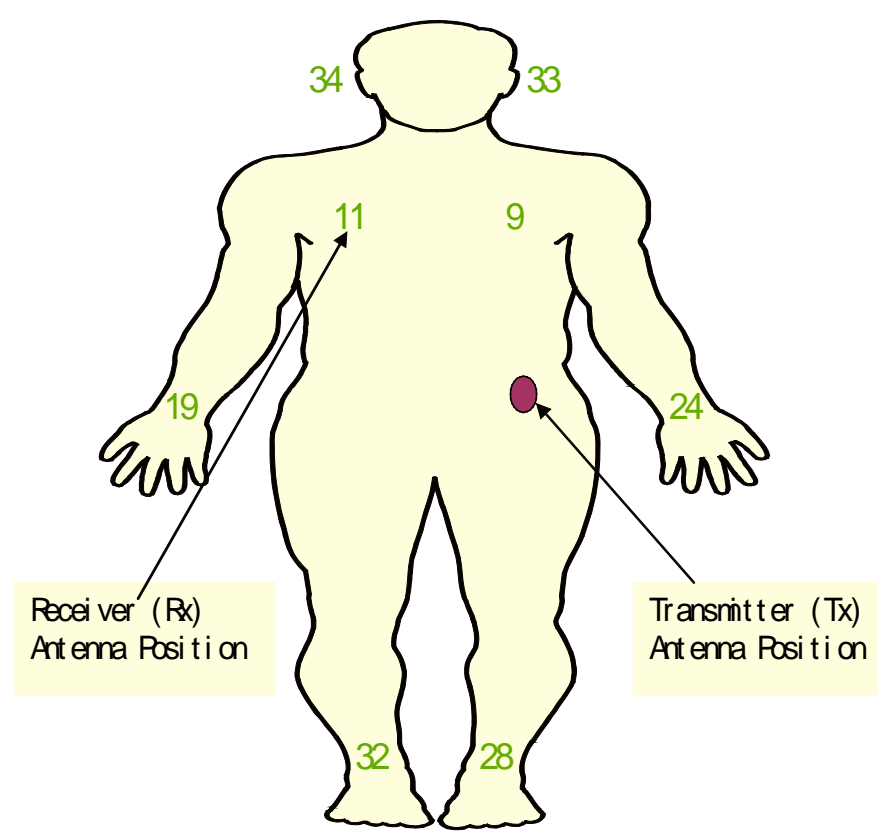

Figure 1. On-body measurement settings showing the transmitter antenna is on the left waist while the receiver antenna is on 8 different locations of the body.

tric Wireless Sensor Laboratory at Queen Mary, University of London. The total area of the lab is $45 \mathrm{~m}^{2}$ which includes a meeting area, treadmill machine, workstations and a hospital bed for healthcare applications. The dimension and geometry of the Body-Centric Wireless Sensor Laboratory are shown in Figure 2.

\section{Antenna Parameters}

The dimensions and geometry of the compact quasi-self-complementary ultra wideband antenna used for this measurement are shown in Figure 3. A half-circular disk with a radius of $6 \mathrm{~mm}$ and its complementary magnetic counterpart are printed on the different side of the dielectric substrate. The small printed quasi-self-complementary antenna is fed by a microstrip line. The antenna is fabricated on FR4 substrate with thickness of $h=$ $1.6 \mathrm{~mm}$ and relative permittivity of $\varepsilon_{r}=3$. The length and the width of the substrate for this antenna are 25 and $16 \mathrm{~mm}$, respectively. The total size of the antenna is $25 \times 16 \mathrm{~mm}^{2}$ which is around $0.25 \lambda_{0} \times 0.16 \lambda_{0}$ in electrical length, where, $\lambda_{0}$ is the free space wavelength at $3 \mathrm{GHz}$. The antenna size is not only physically small, but also electrically small. A triangular slot is cut on the ground plane in order to improve the impedance matching of the antenna. There is a partial ground plane at the back of the self complementary compact ultra wideband antenna [23]. The S11 measurement campaigns of the proposed UWB antenna were performed in an anechoic chamber. The return loss was first measured in free space and then the antenna was placed directly on the body (left side of the waist), and at 1, 4, 8 and $16 \mathrm{~mm}$ away from the body. Figure 4 shows the free space and on-body return loss responses of the used compact UWB antenna when placed at various distances away from the human body. The figure illustrates that the antenna has excellent impedance matching across the UWB band, with return loss less than $-10 \mathrm{~dB}$. This antenna shows very good radiation patterns, radiation efficiency and gain when placed on the human body as reported in [24]. More detail analysis about antenna return loss, radiation pattern, efficiency and gain can be found in [24].

\section{Ultra Wideband On-Body Radio Channel Parameters}

\subsection{On-Body Radio Channel Characterisation}

The path loss for each receiver location is directly calculated from the measurement, averaging over the frequency band of 3 - $10 \mathrm{GHz}$. In this study, the path loss for eight different on-body radio channels has been characterised and investigated (see Figure 1). A comparison of path loss for eight different on-body radio channels 


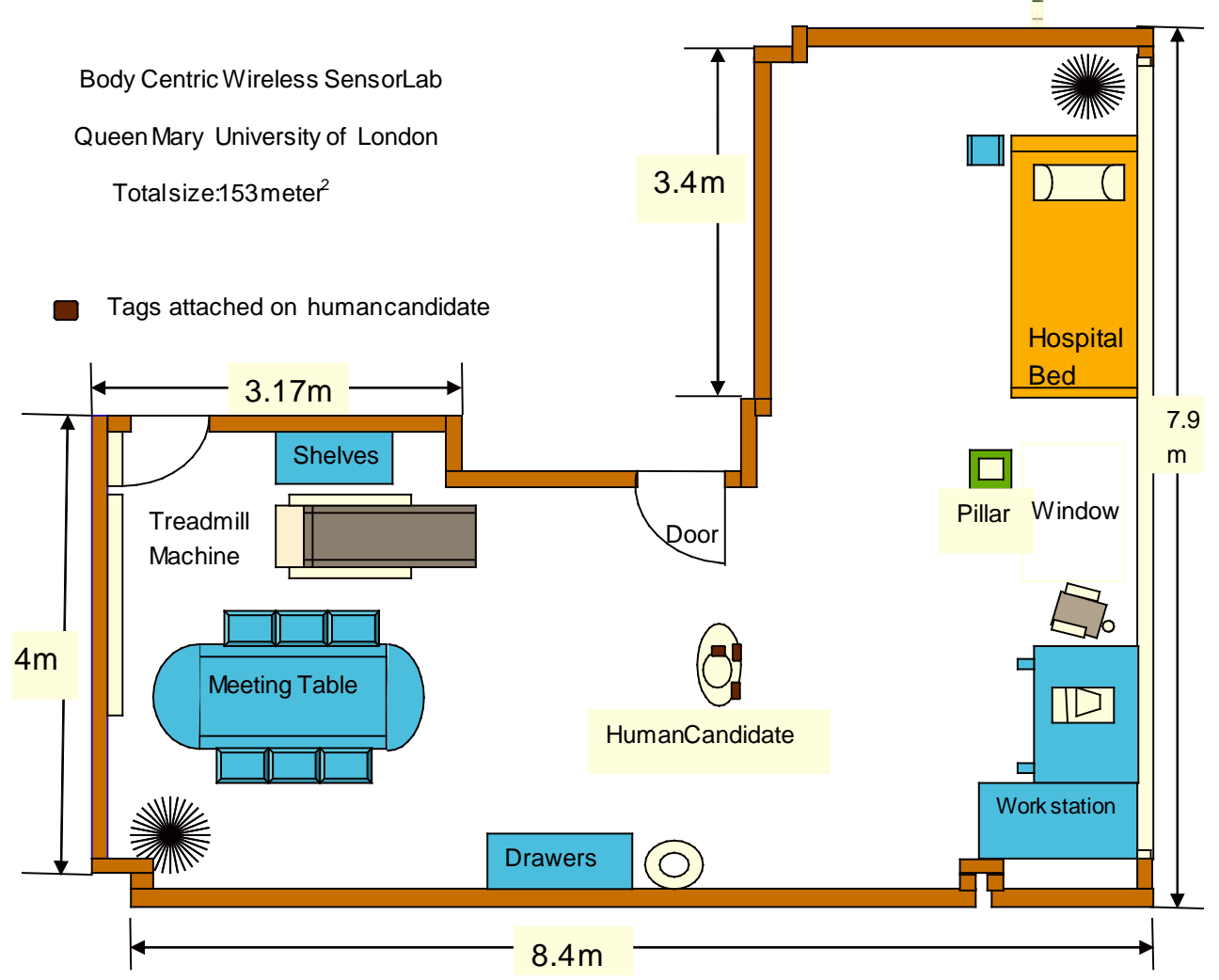

Figure 2. Dimension and geometry of the body-centric wireless sensor laboratory where the indoor on-body radio propagation measurements for the presented study is performed.

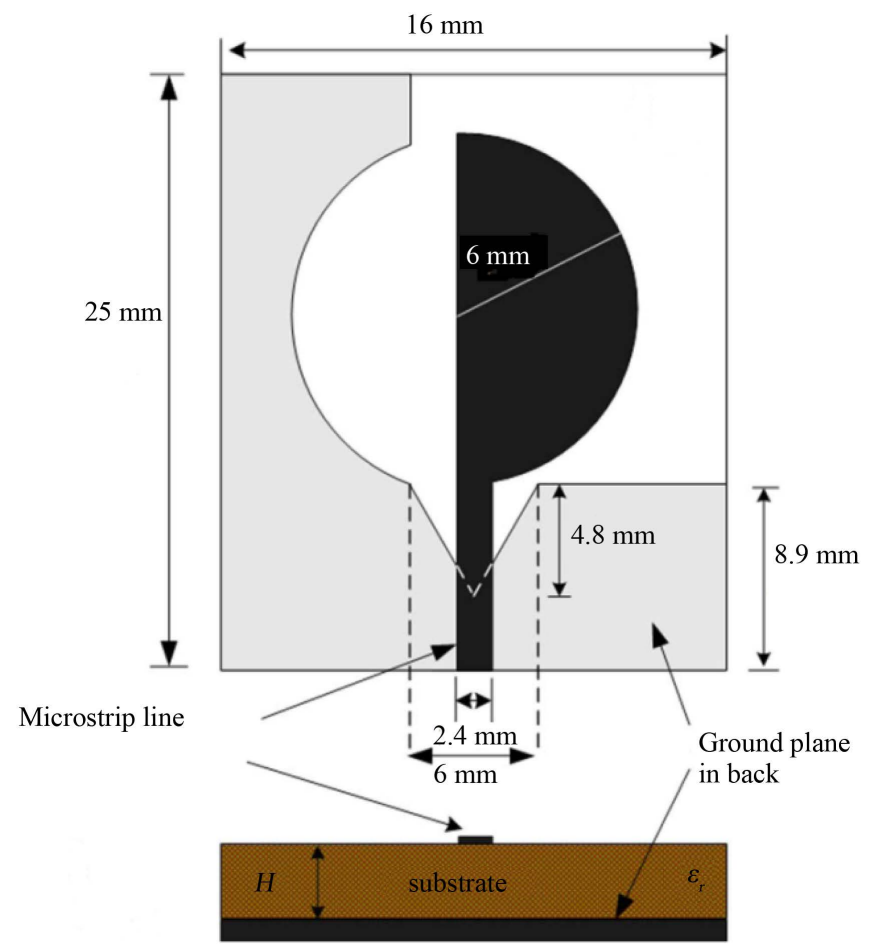

Figure 3. Dimension and geometry of the quasi-self-complementary ultra wideband antenna used for this experiment [22]. 


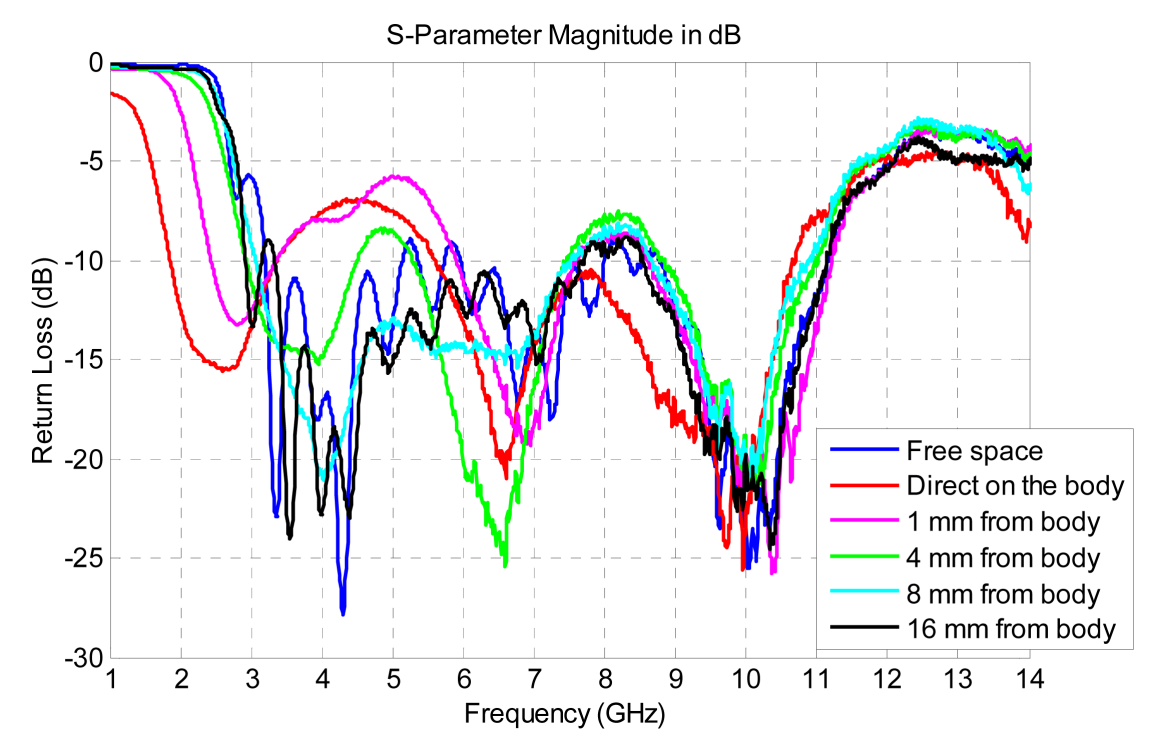

Figure 4. Return loss responses of the tested compact UWB antenna when placed at various distances away from the human body (left side of the waist).

measured in the anechoic chamber and in an indoor environment using compact quasi-self-complementary ultra wideband antenna is shown in Figure 5. Both in the chamber and in an indoor, the highest path loss is noticed for the transmitter to right-wrist link, while the lowest is noticed for the transmitter to left-chest and left-ankle links. In this case, for the transmitter to right-wrist wrist link, the communication distance between the receiver antenna and the transmitter antenna is larger; in addition, there is a presence of non-line-of-sight (NLOS) communications, which cause the highest path loss value for this channel. For the left waist to right-wrist link, the propagation mechanism is mainly creeping waves, which experience higher signal attenuation, resulting in higher path loss value. On the other hand, for the left ankle and left-chest links, there is a clear line-of-sight (LOS) communication which causes the lowest path loss values for these two channels. Although the communication distance for the transmitter to the left ankle link is large, the path loss value is low which can be due to the contribution of ground reflection from the indoor environment. Due to the non-reflecting environment, most of the on-body channels experience higher path loss value when measurements are made in the chamber. In the indoor environment due to reflecting area and contributions of multipath reflection most of the on-body channels experience lower path loss value compared with chamber. The average path loss of all eight on-body radio channels in the chamber is $65.72 \mathrm{~dB}$ whereas $63.71 \mathrm{~dB}$ is found in the indoor environment. Although the size of this antenna is compact, it shows very good on-body radio channels behavior/performance.

\subsection{Path Loss vs. Distance}

In this section, the path loss was modeled as a function of distance for 34 different receiver locations for propagation along the front part of the body. During this measurement, the compact transmitter UWB antenna was placed on the left waist and the receiver antenna was attached on 34 different locations on the front part of the body as shown in Figure 6. It is well known that the average received signal decreases logarithmically with distance for both indoor and outdoor environments as explained in [25].

$$
P L_{d B}(d)=P L_{d B}\left(d_{0}\right)+10 \gamma \log \left(\frac{d}{d_{0}}\right)+X_{\sigma}
$$

where $d$ is the distance between transmitter and receiver, $d_{0}$ is a reference distance set in measurement (in this study it is set to $10 \mathrm{~cm}), P L_{d B}\left(d_{0}\right)$ is the path loss value at the reference distance, and $X_{\sigma}$ is the shadowing fading. The parameter $\gamma$ is the path loss exponent that indicates the rate at which the path loss increases with distance.

In order to extract the path loss exponent a least-square fit technique was performed on the measured path loss for the 34 different receiver locations (Figure 6). Figure 7 shows the measured value and modelled path loss 


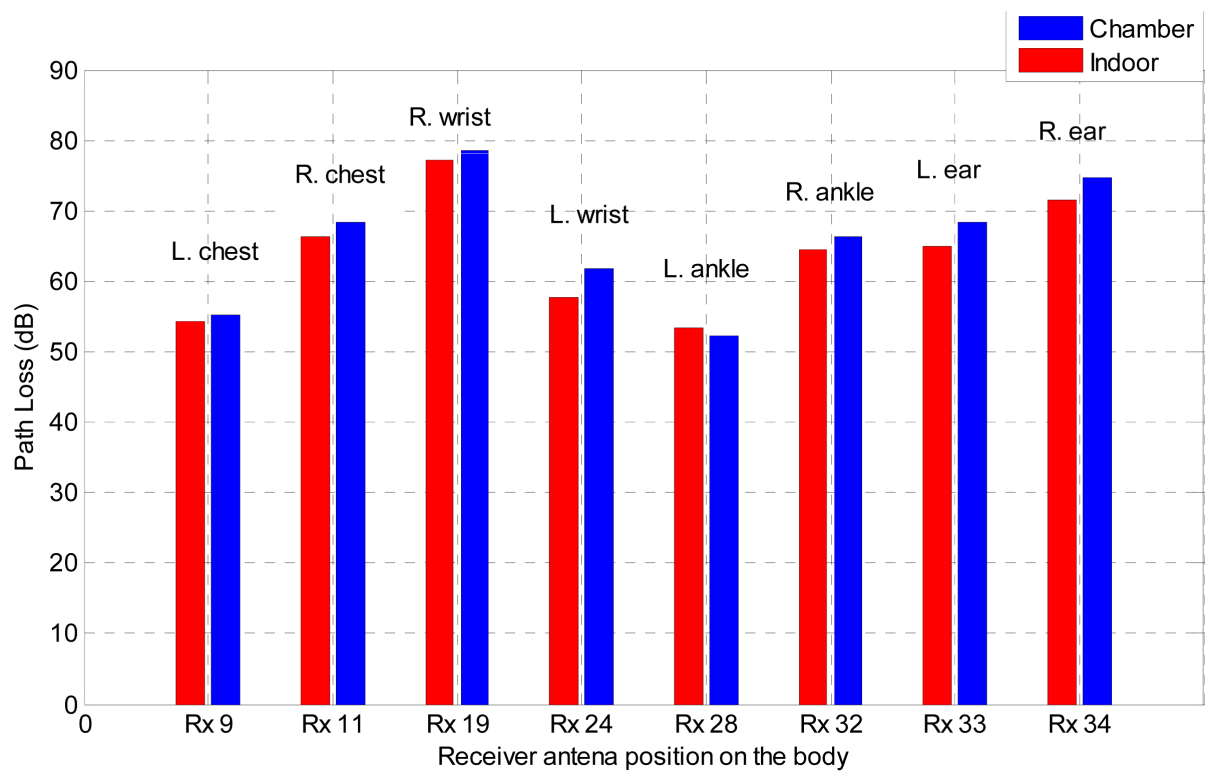

Figure 5. Comparison of path loss for eight different on-body radio channels measured in the chamber and in an indoor environment for the tested compact UWB antenna used in this study.

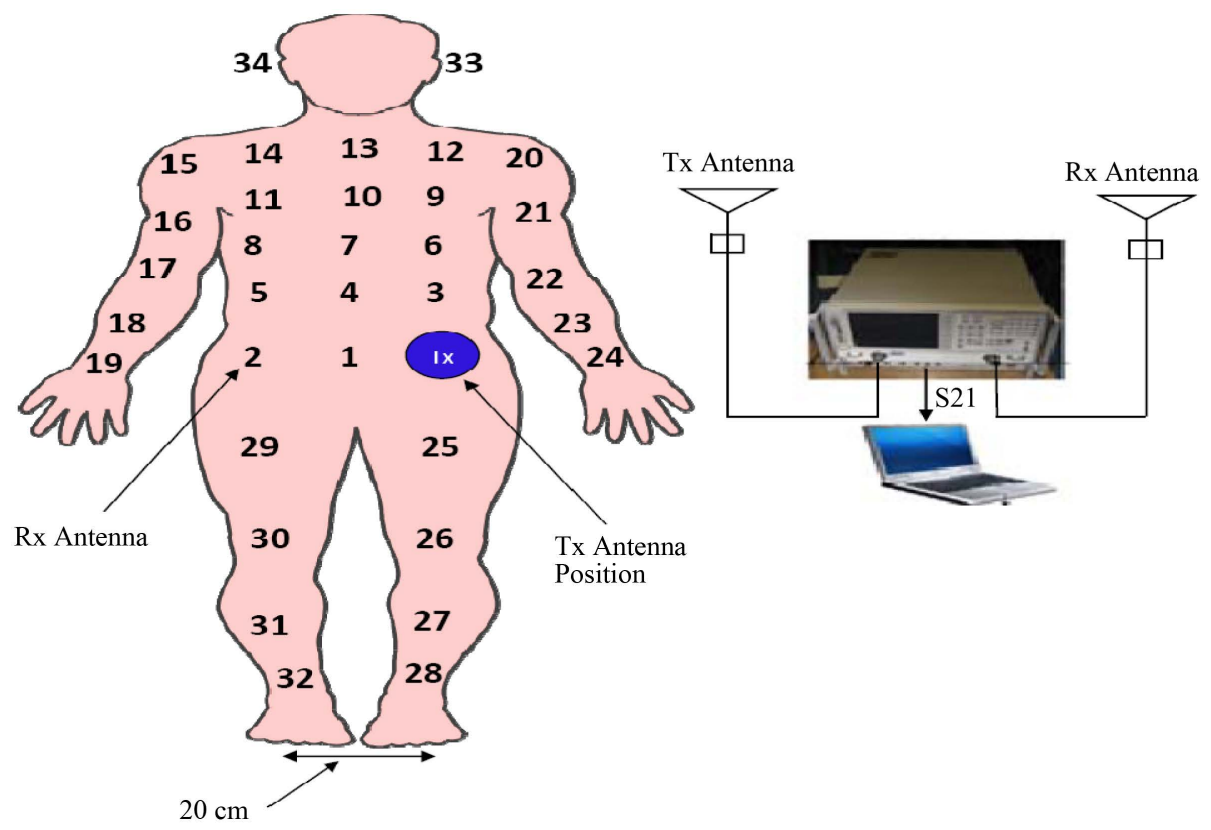

Figure 6. UWB on-body measurement settings showing the transmitter antenna is on the left waist while the receiver antenna is on 34 different locations of the body.

for on-body channels versus logarithmic Tx-Rx separation distance. In this study, the path loss exponent was found to be 2.57 in the chamber and 2.15 in indoor (Table 2). In the indoor environment, the path loss exponent was found to be lower compared to chamber. When measurements are performed indoor, the reflections from surroundings scatters increase the received power, causing reduction in the path loss exponent. A reduction of $16.34 \%$ was noticed in indoor compared to the chamber in this case.

$X_{\sigma}$ is a zero mean, normal distributed statistical variable, and is introduced to consider the deviation of the measurements from the calculated average path loss. Figure 8 shows the deviation of measurements from the average path loss fitted to a normal distribution for both measurement cases. In this case, the standard deviation 


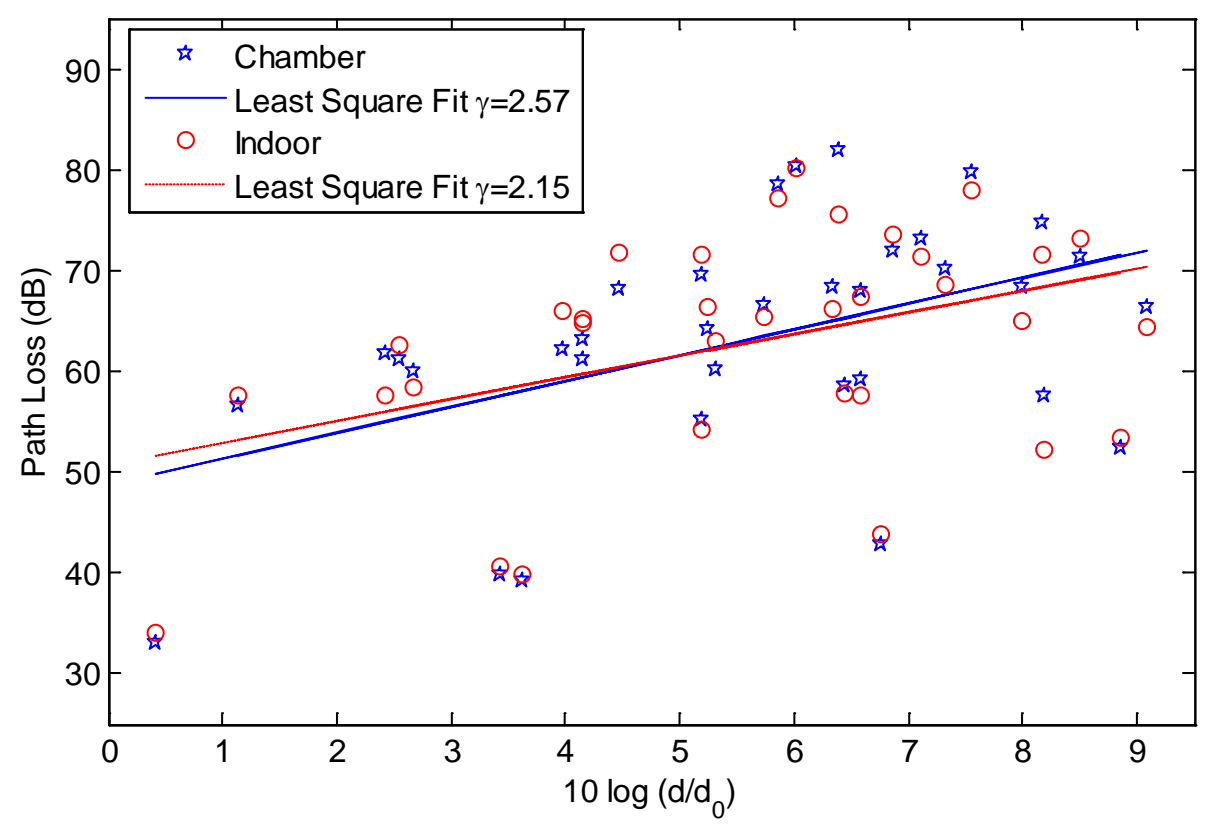

Figure 7. Measured and modelled path loss for on-body channel versus logarithmic (Tx) and receiver $(\mathrm{Rx})$ separation distance for tested compact quasi-self-complementary UWB antenna.

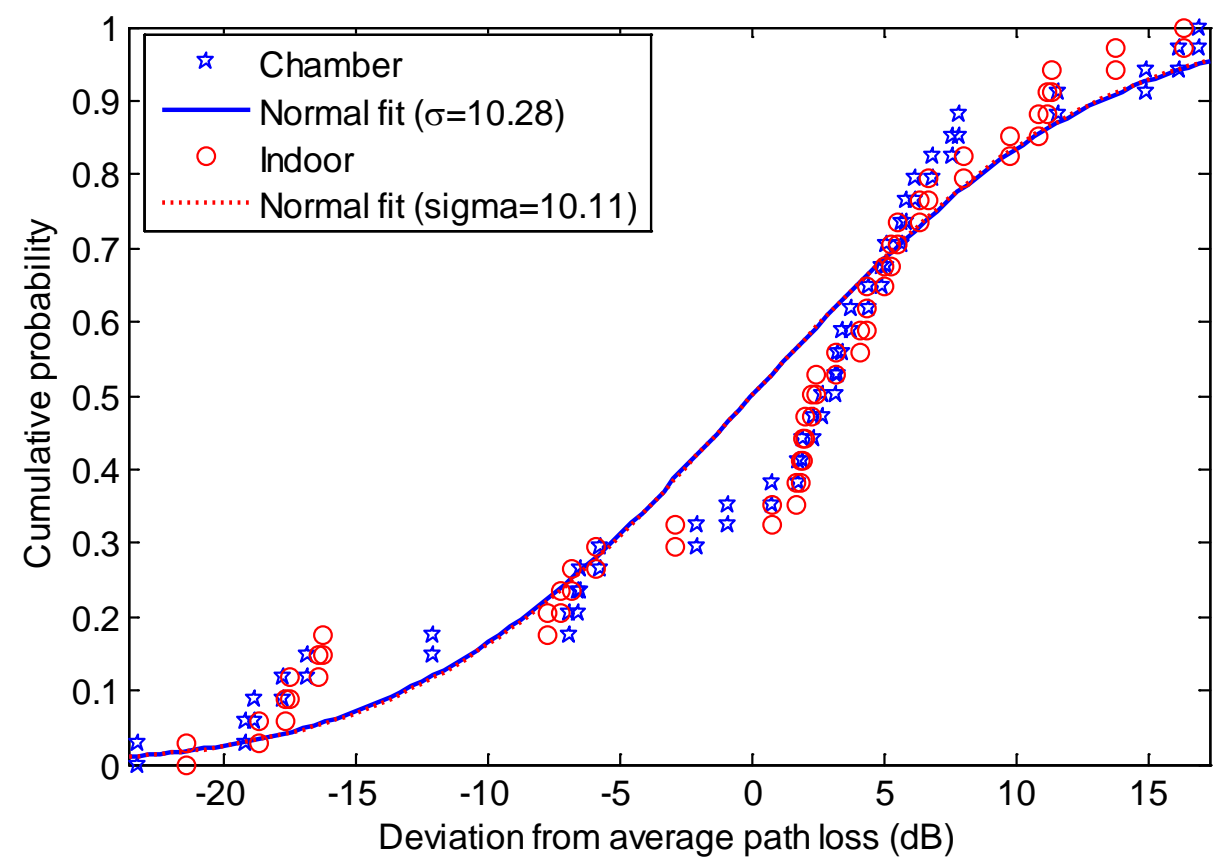

Figure 8. Deviation of the measurements from the average path loss (fitted to normal distribution) for the tested compact UWB antenna used in this experiment.

Table 2. Path loss parameters of the tested compact UWB antenna used in this experiment.

\begin{tabular}{ccc}
\hline Path loss parameters & Chamber & Indoor \\
\hline$\gamma$ & 2.57 & 2.15 \\
$P L_{d B}\left(d_{0}\right)(\mathrm{dB})$ & 49.0 & 50.8 \\
$\sigma(\mathrm{dB})$ & 10.28 & 10.11 \\
\hline
\end{tabular}


of the normal distribution is found to be slight lower in the indoor environment (Table 2).

\section{Conclusion}

In this paper, ultra wideband on-body radio propagation channel measurements were performed using compact quasi-self-complementary ultra wideband antenna in the chamber and indoor environment. Eight different onbody radio channels have been investigated and analyzed. Path loss parameters of this proposed antenna are investigated for both chamber and indoor environment cases. In this study, the highest path loss is noticed for the transmitter to right-wrist link, while the lowest is noticed for the transmitter to left-chest and left-ankle links. Due to its compact size and very good on-body radio channel performance, the printed quasi-self-complementary ultra wideband antenna will be a proper candidate for reliable and efficient communications in UWB wireless body area networks.

\section{Acknowledgements}

The authors of this paper would like to thank John Dupuy for his help with the antenna fabrication. The authors also would like to thank Sanjoy Mazumdar for his help during the measurement.

\section{References}

[1] Hall, P.S. and Hao, Y. (2006) Antennas and Propagation for Body-Centric Communications. Artech House, London and Boston.

[2] Foerester, J., Green, E., Somayazulu, S. and Leeper, D. (2001) Ultra-Wideband for Short- or Medium-Range Wireless Communications. Intel Technology Journal, Q2.

[3] Fort, A., Desset, C., Doncker, P.D. and Biesen, L.V. (1820) Ultra Wideband Body Area Propagation: From Statistics to Implementation. IEEE Transactions on Microwave Theory and Technique, 54, 1826.

[4] Kunze, C., Grossmann, U., Stork, W. and Muller-Glaser, K. (2002) Application of Ubiquitous Computing in Personal Health Monitoring Systems. Biomedizinische Technik, 47, 360-362. http://dx.doi.org/10.1515/bmte.2002.47.s1a.360

[5] Timmons, N.F. and Scanlon, W.G. (2004) Analysis of the Performances of IEEE 802.15.4 for Medical Sensor Body Area Networking. 2004 First Annual IEEE Communications Society Conference on Sensor and Ad Hoc Communications and Networks, 4-7 October 2004, 16-24. http://dx.doi.org/10.1109/SAHCN.2004.1381898

[6] WSN for Healthcare: A Market Dynamics Report (2008). http://www.onworld.com/healthcare/index.html

[7] Presser, M., Brown, T., Goulianos, A., Stavrou, S. and Tafazolli, R. (2007) Body-Centric Context Aware Application Scenarios. Proceedings of the IET Seminar on Antennas and Propagation for Body-Centric Wireless Communications, London, 24-24 April 2007, 19-23. http://dx.doi.org/10.1049/ic:20070540

[8] Khan, M.M., Abbasi, Q.H., Alomainy, A. and Parini, C. (2014) Experimental Investigation of Subject Specific OnBody Radio Propagation Channels for Body-Centric Wireless Communications. Electronics, 3, 26-42. http://dx.doi.org/10.3390/electronics3010026

[9] Alomainy, A., Hao, Y., Owadally, A., Parini, C.G., Hall, P.S. and Constantinou, C.C. (2007) Statistical Analysis and Performance Evaluation for On-Body Radio Propagation with Microstrip Patch Antennas. IEEE Transactions on Antenna and Propagation, 55, 245-248. http://dx.doi.org/10.1109/TAP.2006.888462

[10] Hall, P.S., Hao, Y., Nechayev, Y.I., Alomainy, A., Constantinou, C.C., Parini, C.G., Kamruddin, M.R., Salim, T.Z., Hee, D.T.M., Dubrovka, R., Wadally, A., Song, W., Serra, A., Nepa, P., Gallo, M. and Bozzetti, M. (2007) Antennas and Propagation for On-Body Communication Systems. IEEE Antennas and Propagation Magazine, 49, 41-58. http://dx.doi.org/10.1109/MAP.2007.4293935

[11] Nechayev, Y.I., Hall, P.S. and Hu, Z.H. (2010) Characterisation of Narrowband Communication Channels on the Human Body at 2.45 GHz. IET Microwaves, Antennas and Propagation, 4, 722-732. http://dx.doi.org/10.1049/iet-map.2009.0094

[12] Nechayev, Y., Hall, P., Constantinou, C.C., Hao, Y., Owadally, A. and Parini, C.G. (2004) Path Loss Measurements of On-Body Propagation Channels. Proceedings of the 2004 International Symposium on Antennas and Propagation, Sendai, 17-21 August 2004, 745-748.

[13] Hall, P.S., Nechayev, Y., Hao, Y., Alomainy, A., Kamaruddin, M.R., Constantinou, C.C., Dubrovka, R. and Parini, C.G. (2005) Radio Channel Characterisation and Antennas for On-Body Communications. Proceedings of the Loughborough Antennas and Propagation Conference, Loughborough, 4-6 April 2005, 330-333. 
[14] Hao, Y., Alomainy, A., Hall, P.S., Nechayev, Y.I., Parini, C.G. and Constantinou, C.C. (2005) Antennas and Propagation for Body-Centric Wireless Communications. Proceedings of the IEEE/ACES International Conference on Wireless Communications and Applied Computational Electromagnetics, Honolulu, 3-7 April 2005.

[15] Hu, Z., Nechayev, Y., Hall, P.S., Constantinou, C. and Hao, Y. (2007) Measurements and Statistical Analysis of OnBody Channel Fading at 2.45 GHz. IEEE Antennas and Wireless Propagation Letters, 6, 612-615. http://dx.doi.org/10.1109/LAWP.2007.904633

[16] Alomainy, A., Hao, Y. and Pasveer, F. (2007) Numerical and Experimental Evaluation of a Compact Sensor Antenna for Health Care Devices. IEEE Transactions on Medical Circuits and Systems, 1, 242-249. http://dx.doi.org/10.1109/TBCAS.2007.913127

[17] Wang, Q. and Wang, J. (2009) Performances of On-Body Chest-to-Waist UWB Communication Link. IEEE Microwave and Wireless Components Letters, 19, 119-121.

[18] Wang, Q., Tayamachi, T., Kimura, I. and Wang, J. (2009) An On-Body Channel Model for UWB Body Area Communications for Various Postures. IEEE Journal on Selected Areas in Communications, 57, 991-998.

[19] Sani, A. and Hao, Y. (2009) Modeling of Path Loss for Ultrawide Band Body Centric Wireless Communications. Proceedings of the International Conference on Electromagnetics in Advance Applications, Torino, 14-18 September 2009, 998-1001.

[20] Alomainy, A., Hao, Y., Parini, C.G. and Hall, P.S. (2005) On Body Propagation Channel Characterization for UWB Wireless Body Centric Networks. Proceedings of the 2005 IEEE Antennas and Propagation Society International Symposium, Washington DC, 694-697.

[21] Alomainy, A.A., Hao, Y., Parini, C.G. and Hall, P.S. (2005) Comparison between Two Different Antennas for UWB On-Body Propagation Measurements. IEEE Antennas and Wireless Propagation Letters, 4, 31-34. http://dx.doi.org/10.1109/LAWP.2005.844143

[22] Alomainy, A., Sani, A., Rahman, A., Santas, J.G. and Hao, Y. (2009) Transient Characteristics of Wearable Antennas and Radio Propagation Channels for Ultrawideband Body-Centric Wireless Communications. IEEE Transactions on Antennas and Propagations, 57, 875-884.

[23] Guo, L., Wang, S., Chen, X. and Parini, C.G. (2009) A Small Printed Quasi-Self-Complementary Antenna for Ultrawideband Systems. IEEE Antennas and Wireless Propagation Letters, 8, 554-557.

[24] Khan, M.M., Mobin, I., Palikaras, G. and Kallos, E. (2012) Study of a Small Printed Quasi-Self-Complementary Ultra Wideband Antenna for On-Body Applications. Proceedings of the 4th Computer Science and Electronic Engineering Conference, Colchester, 12-13 September 2012, 179-183.

[25] Gassemzadeh, S.S., Jana, R., Rice, C.W., Turin, W. and Tarohk, V. (2002) A Statistical Path Loss Model for In-Home UWB Channels. Proceedings of the 2002 IEEE Conference on Ultra Wideband Systems and Technologies, Baltimore, 21-23 May 2002, 59-64. 